\title{
Study on Damage Characteristic of Underground Cavern Blasting Excavation Based on Dynamic Damage Constitutive Model
}

\author{
Qian Dong ${ }^{1,2, a}$, Xinping $\mathrm{Li}^{1, \mathrm{~b}}$ and Hang Zhao ${ }^{1,2}$ \\ ${ }^{1}$ Hubei Key Laboratory of Roadway Bridge \& Structure Engineering, Wuhan University of \\ Technology, Wuhan, China \\ ${ }^{2}$ School of Civil Engineering \& Architecture, Wuhan University of Technology, Wuhan, China \\ adongqianse@126.com, ${ }^{\mathrm{b} x i n p i n g l i @ w h u t . e d u . c n ~}$
}

Keywords: Blasting damage model, Damage criteria, Smooth blasting, Blasting parameters

\begin{abstract}
The dynamic disturbance to the remaining surrounding rock mass of underground caverns produced by blasting excavation can not be ignored. Considering the rock mass damage induced by compression-shear stress in the zone near the blasthole, the KUS dynamic damage constitutive model was improved, and adding the defined damage discrimination value to the KUS model.Using the improved KUS damage model to conduct the numerical calculation of the Xiluodu hydropower station left-bank underground powerhouse, to study the recommended smooth blasting parameters of side wall protective layer rock mass of underground powerhouse. The results show that the damage depth of rock mass around the blasthole was influenced by the cartridge diameter of blasthole, the increasing of the hole spacing only changed the shape of the damage zone, and can not reduce the maximum damage depth.In engineering design, the cartridge diameter of blasthole and the hole spacing can not be enlarged optionally, must be strictly in accordance with the requirements of the blasting design.
\end{abstract}

\section{Introduction}

Traditional rock mass blasting damage constitutive models such as GK, TCK, KUS, and YANG, which are all based on the expansion of micro cracks in rock mass under the explosion shock loading, and defining different damage factors.But most of traditional blasting damage constitutive models only considered the rock mass damage caused by the tensile stress, it is not fully considered the damage induced by compression-shear stress in the area near by blasting source.Therefore, the calculated damage range of the rock mass near the explosion impact load is not accurate enough.

On the basis of the TCK damage model, Yang considered the attenuation law of acoustic in the process of rock mass damage, and got a new model of rock mass blasting damage,the model was embedded into the LS-DYNA3D dynamic finite element software[1].Wang modified TCK with the general bilinear and elastic-plastic constitutive, and embedded the modified model into the dynamic finite element analysis software LS-DYNA, the rationality and accuracy of the model were verified by the engineering examples[2].Li based on Yang-Liu damage model, and took the damage variable into the elastic-plastic constitutive equation, studied the damage range and criterion of Xiluodu hydropower station underground powerhouse rock mass by numerical simulation method and in-situ blasting vibration test[3].Xiao coupled the Mohr-Coulomb elastic-plastic constitutive and Yang-Liu rock mass damage model, simulated the damage characteristics of a circular tunnel surrounding rock mass failure process[4].Meng based on the blasting crater test, established the improved H-J-C rock mass blasting damage constitutive model by considering the damage caused by tensile stress,through the LS-DYNA software, study on blasting crater formation process[5].According to the measured data of surrounding rock acoustic wave test, the KUS damage constitutive model of rock mass was improved by RDA model, it was showed that the numerical results of this model was close to the measured data[6].

In this paper, the KUS dynamic damage constitutive model was improved, by considering the rock mass damage induced by compression-shear stress, and adding the defined damage discrimination value to the KUS model.Therefore using the improved KUS damage model to conduct the numerical 
calculation of the Xiluodu hydropower station left-bank underground powerhouse, to study the recommended smooth blasting parameters of protective layer rock mass of underground powerhouse side wall.

\section{The establishment of the defined dynamic damage constitutive model}

In this paper, an improved KUS damage constitutive model was adopt, the computational theory and the framework of this constitutive model was elastic-plastic constitutive equation of isotropic hardening. In the elastic stage, the constitutive model used generalized Hooke's law, the calculation formula as shown in Eq.1.

$$
\sigma=E \varepsilon
$$

Where, $\sigma, \varepsilon$ are stress and strain of rock mass, $E$ is the elastic modulus of rock mass.

In the KUS damage constitutive model, the tensile strength of rock mass is much less than the compressive strength[7]. Therefore, when the rock is in the three direction loading, the micro cracks growth when the rock mass under volumetric tensile stress, and calculation formula of crack density $C_{d}$ as shown in Eq.2.

$$
C_{d}=\frac{5}{2} k m\left[\frac{K_{I C}}{\rho C_{P} \dot{\varepsilon}_{\max }}\right]^{2} \varepsilon^{m-1} \dot{\varepsilon}(1-D)
$$

Where, $\varepsilon_{\max }$ is the maximum volumetric strain rate, $\rho, C_{P}$ and $K_{I C}$ are the density, p-wave velocity and fracture toughness of rock mass, $D$ is the damage factor of rock mass under blasting load, $k, m$ are the material parameters. The mechanical parameters of damaged rock mass as shown in Eq.3.

$$
\bar{E}=E(1-D) ; \bar{K}=K(1-D) ; \bar{G}=\frac{3(1-2 \mu)}{2(1+\mu)} \bar{K}
$$

Where, $K, G, \bar{K}, \bar{G}$ are the bulk and shear modulus before and after rock mass damaged.The incremental Hooke law of rock mass contains the blasting damage as shown in Eq.4.

$$
d \sigma_{i j}=\bar{K} d \varepsilon_{k k} \delta_{i j}+2 \bar{G} d e_{i j}
$$

Where, $\sigma_{i j}, \varepsilon_{i j}$ and $e_{i j}$ are stress, volumetric strain and deviatoric strain tensor respectively.The incremental theory of plastic mechanics was adopted after rock mass reached the yield stage, by using isotropic hardening criterion for determining the plastic stress state of rock mass. In the rock mass area near blasting source, although the compressive strength of rock mass is much greater than the tensile strength, but the explosive load near blasting source is in the large scale, will lead to the compression-shear damage of rock mass.Based on a large amount of research works, the ratio of the principal stress difference to the uniaxial compressive strength of rock mass was used as the discriminant value $F_{d}$ of rock mass damaged degree as shown in Eq.5.

$$
F_{d}=\frac{\sigma_{1}-\sigma_{3}}{\sigma_{c d}}
$$

Where, $\sigma_{1}, \sigma_{3}$ are the maximum and minimum principal stress of rock mass, $\sigma_{c d}$ is the dynamic compressive strength of rock mass.In the defined dynamic damage constitutive model of this paper, the discriminant value $F_{d}$ was embedded in the defined model through the FORTRAN language,and wrote in LS-DYNA program.The value $F_{d}$ calculated at each load substep in LS-DYNA program. According to the safety vibration velocity standard, the damage threshold $C$ was derived,when the value of $F_{d}$ exceed the value of damage threshold $C$, it can be considered rock mass into the compression-shear damage state, and each modulus got further reduced in Eq.3 as shown in Eq.6.

$$
E^{\prime}=C_{f d} \bar{E}, K^{\prime}=C_{f d} \bar{K}, G^{\prime}=C_{f d} \bar{G}
$$

Where, $C_{f d}$ is the reduction factor, the calculation formula as shown in Eq.7. 


$$
C_{f d}=\left\{\begin{array}{c}
1, F_{d} \leq C \\
\left(F_{d}-C+1\right)^{-a}, F_{d}>C
\end{array}\right.
$$

Where, the value $F_{d}$ calculated at each load substep in LS-DYNA program,the value of $C$ and $\alpha$ are 0.3 and 0.2 according to numerical calculation.

\section{The damage law of underground powerhouse protective layer under blasting excavation}

According to the excavation data and spatial dimension of underground powerhouse protective layer,the numerical model was established as shown as in Fig 1 and 2.

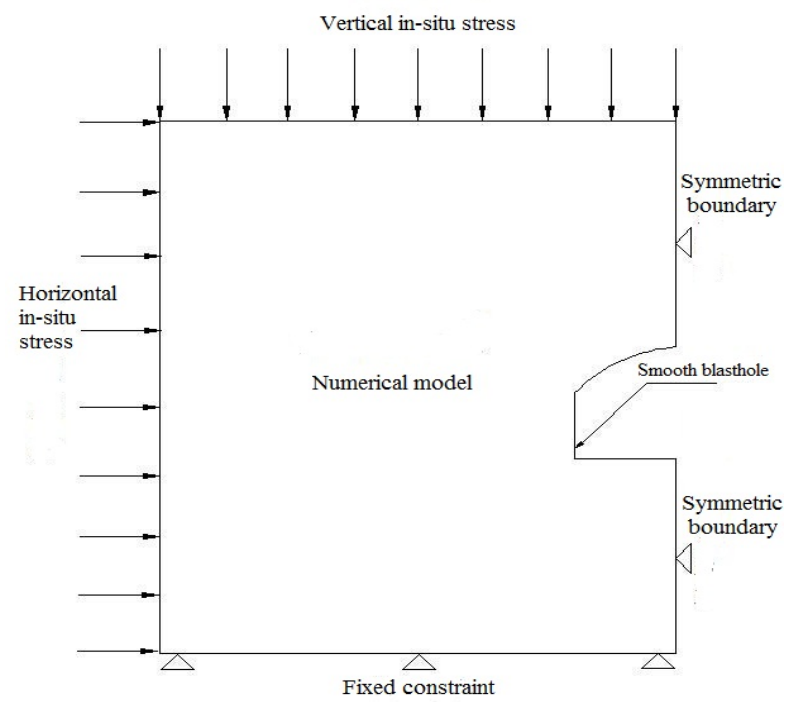

Fig.1 Application of in-situ stress and constrains

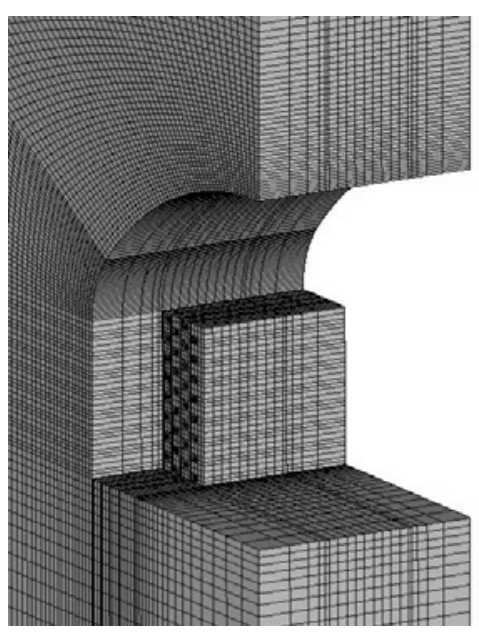

Fig.2 Sketch of numerical model

The whole numerical model is meshed into 378374 3D solid164 elements, and due to the symmetric of numerical model, in the numerical calculation, it only need take half of the model to be calculated. Symmetric boundaries are applied on the symmetry planes, and non-reflective boundaries are applied to the other outer boundary.The material parameters of rock mass in diversion tunnel groups is shown in Table 1.

\begin{tabular}{ccccccc}
\hline \multirow{2}{*}{ Density } & $\begin{array}{c}\text { Elastic } \\
\text { modulus }\end{array}$ & $\begin{array}{c}\text { Tangent } \\
\text { modulus }\end{array}$ & $\begin{array}{c}\text { Cohesive } \\
\text { strength }\end{array}$ & $\begin{array}{c}\text { Friction } \\
\text { angle }\end{array}$ & $\begin{array}{c}\text { Compressive } \\
\text { strength }\end{array}$ & $\begin{array}{c}\text { Poission's } \\
\text { ratio }\end{array}$ \\
\hline $2700 \mathrm{~kg} / \mathrm{m}^{3}$ & $50 \mathrm{GPa}$ & $8 \mathrm{GPa}$ & $2.6 \mathrm{MPa}$ & $50^{\circ}$ & $100 \mathrm{MPa}$ & 0.25 \\
\hline
\end{tabular}

Table 1 Dynamic material parameters of rock masses

In the C-J condition,the average pressure of explosive detonation, for the decoupling charging boreholes, the calculation formula of explosive pressure as shown in Eq.8.

$$
p_{0}=\frac{\rho_{0} D^{2}}{2(1+\gamma)}, p_{m}=p_{0}\left(\frac{d_{c}}{d_{b}}\right)^{2 \gamma}\left(\frac{l_{e}}{l_{b}}\right)^{\gamma} n
$$

Where $p_{0}$ represents average pressure of explosive, $\rho_{0}$ is the density of explosive material, $D$ is the detonation velocity, $\gamma$ is explosive constant,usually takes $3 . p_{m}$ represents maximum explosive pressure on the wall of blasthole in decoupling charging condition, $d_{c}$ is the charge diameter, $d_{b}$ is the borehole diameter, $l_{e}$ is the length of grain, $l_{b}$ is the charging length of blast-holes. $n$ is a pressure enlarging coefficient.

According to the in-situ blasting parameters:detonation velocity and density are $3600 \mathrm{~m} / \mathrm{s}, 950$ $\mathrm{kg} / \mathrm{m}^{3}$, charge and blasthole diameter are $25 \mathrm{~mm}$ and $50 \mathrm{~mm}$ respectively. It's assumed that $l_{e}$ is equal to $l_{b}$, then $p_{m}$ can be calculated to $320.4 \mathrm{MPa}$, and the measured in-situ stress was $10 \mathrm{MPa}$. The numerical calculation time is $1 \mathrm{~s}$, in which the in-situ stress is applied on the rock mass structure in the whole calculation process, and the blasting load is applied to the time period of $0.5-0.517 \mathrm{~s}$, the time of 
peak blasting load is $0.5023 \mathrm{~s}$, and the loading curve is shown in Fig.3.The layout of smooth blastholes in numerical model as shown in Fig.4.

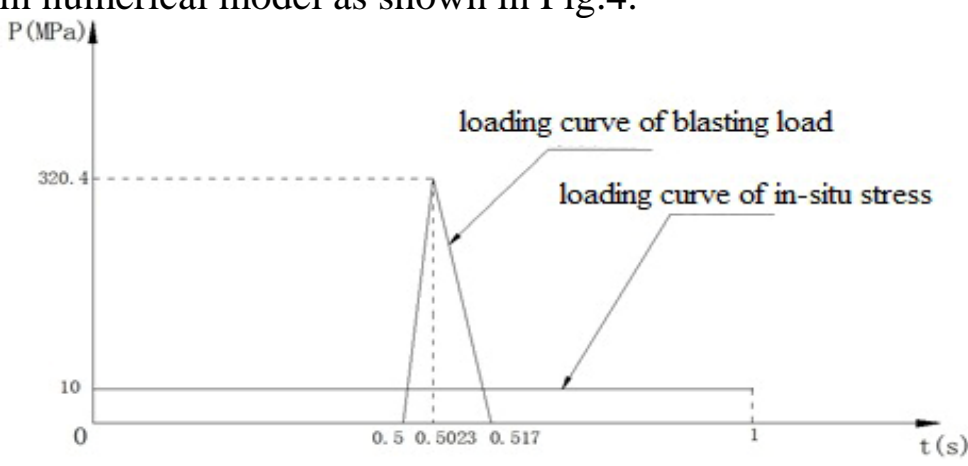

Fig.3 Loading curve of blasting load and in-situ stress

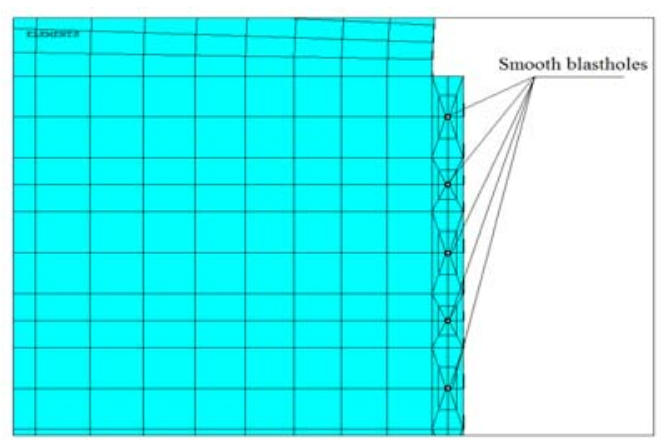

Fig.4 Layout of the smooth blastholes

In order to study the influence of different charge diameter of blasthole on the damage range of surrounding rock, four different conditions were carried for the contrast analysis, the blasthole spacing was kept as a constant $0.5 \mathrm{~m}$ in the numerical simulation. The blast loads applied on the smooth blasthole in four different conditions are respectively 160,320,640, and 960MPa and corresponding charge diameter are 22, 25, 28, and $30 \mathrm{~mm}$, the number of conditions is from 1 to 4 . The distribution figment of the value $F_{d}$ in surrounding rock mass as shown in Fig.5.

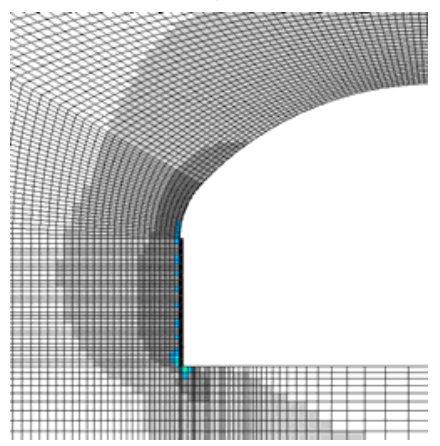

(a) condition 1

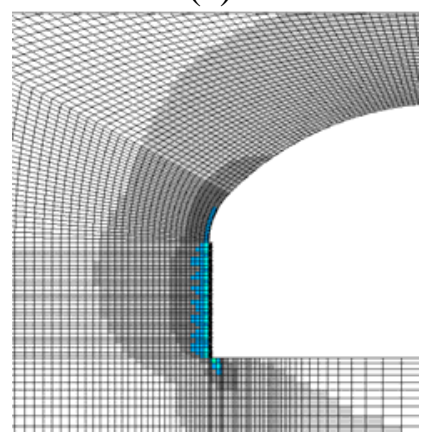

(c) condition 3
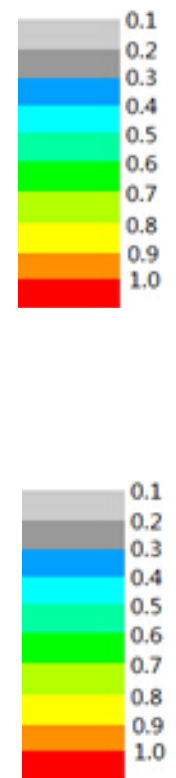

Fig.5 Distribution of the value $F_{d}$ in surrounding rock mass

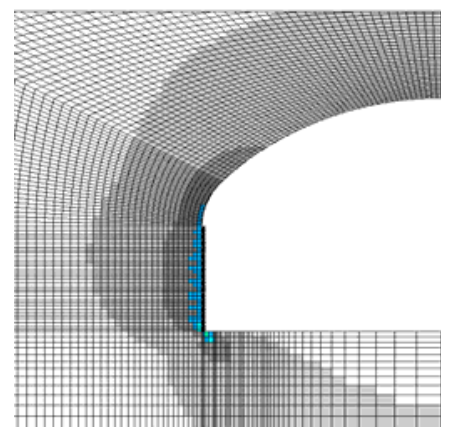

(b) condition 2

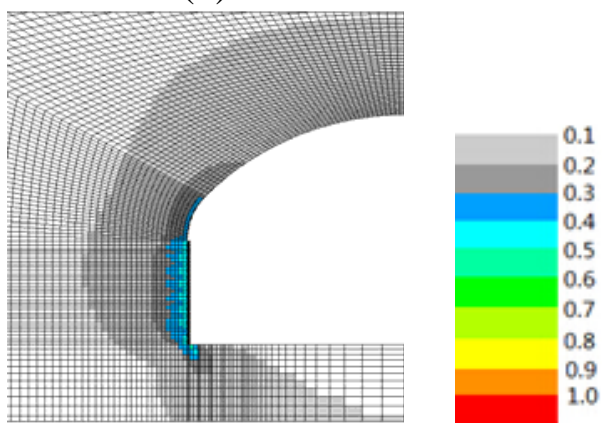

(d) condition 4

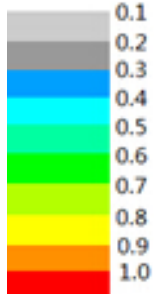

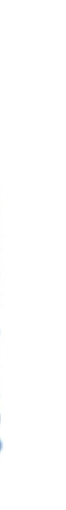

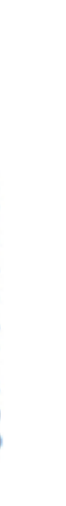


When the blasting load is constant, the maximum damage depth located in the arch foot of surrounding rock mass, and with the increasing of charge diameter, the damage depth of arch foot increasing rapidly than other part of underground powerhouse.

In order to study the influence of different blasthole spacing on the damage range of surrounding rock, two different conditions were carried for the contrast analysis, the blasting load was kept as a constant $320 \mathrm{MPa}$ in the numerical simulation.The blasthole spacing are respectively 0.5 and $1 \mathrm{~m}$. The distribution figment of the value $F_{d}$ in surrounding rock mass as shown in Fig.6 and Fig.7.

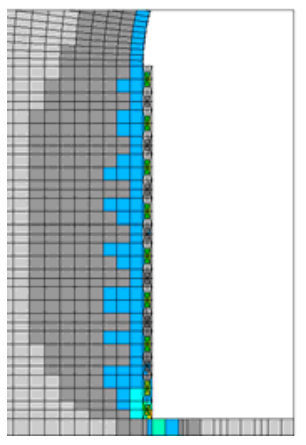

Fig.6 Distribution of the value $F_{d}$ in surrounding rock mass with $1 \mathrm{~m}$ blasthole spacing

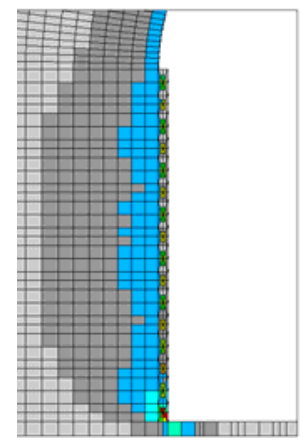

Fig.7 Distribution of the value $F_{d}$ in surrounding rock mass with $0.5 \mathrm{~m}$ blasthole spacing

By comparing the different numerical results of blasthole spacing $0.5 \mathrm{~m}$ and $1 \mathrm{~m}$, it found that the blasting damage range is extended from the center of smooth blasthole. When the hole distance increases, the damage area is serrated, and the damage depth of the two conditions is approximately the same, but the shape of damage area is different.

\section{Conclusion}

The damage depth of the smooth blasting excavation is controlled by the diameter of the charge, although the increase of the hole distance can control the shape of the damage area, but the distribution and depth of the damage area is increased, which is not conducive to the stability of surrounding rock.

\section{Acknowledgements}

This work was financially supported by the National Natural Science Foundation of China (51274157).

\section{References}

[1] YANG Jun, JIN Qian-kun. Explosion and Shock Waves. Vol. 20(3)(2000), p.241-246.(In Chinese)

[2] WANG Zhi-liang, ZHENG Ming-xin. Rock and Soil Mechanics. Vol. 29(1)(2008), p.230-234. (In Chinese)

[3] LI Xinping, CHEN Junhu, LI Youhua, et al. Chinese Journal of Rock Mechanics and Engineering . Vol. 29(10)(2010), p. 2042-2049. (In Chinese)

[4] ZUO Shuang-ying, XIAO Ming, XU Jian-ke, et al. Rock and Soil Mechanics. Vol.32(10)(2011), p. 3171-3176. (In Chinese)

[5] MENG Zhuo-chao, ZHOU Ke-ping. Journal of Central South University(Science and Technology) . Vol. 43(7)(2012), p.2717-2722.(In Chinese)

[6] HU Ying-guo, LU Wen-bo, CHEN Ming, et al. Rock and Soil Mechanics. Vol.33(11)(2012), p. 3278-3284. (In Chinese)

[7] KUSZMAUL J S. Proceedings of the 2nd International Symposium on Rock Fragmentation by Blasting. Canada: Keystone, 1987: 412-423. 